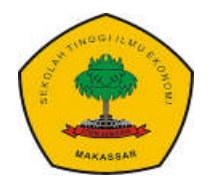

Issue 2 (Oktober, 2017)

\title{
PENGARUH PEMBERDAYAAN TERHADAP KEPUASAN KERJA KARYAWAN
}

\author{
Bariya Samiun 1), Herman Sjaharuddin²), Suseno H. Purnomo ${ }^{3)}$ \\ bhilabhilss@gmail.com \\ 1) Mahasiswa Program Studi Manajemen pada Sekolah Tinggi Ilmu Ekonomi Bongaya \\ Makassar \\ 2,3) Dosen Program Studi Manajemen pada Sekolah Tinggi Ilmu Ekonomi Bongaya \\ Makassar
}

\begin{abstract}
ABSTRAK
Penelitian ini mengeksplorasi pengaruh pemberdayaan karyawan pada dimensi Arti Pekerjaan, Kompetensi, Kebebasan Diri, terhadap Kepuasan Kerja Karyawan pada PT Bank BRI (Persero) Tbk. Cabang Ahmad Yani Makassar. Pengumpulan data menggunakan data primer yang diperoleh dari kuesioner dengan menggunakan sample jenuh. Populasi sekaligus sebagai sampel adalah seluruh Karyawan yang jumlahnya 70 Karyawan. Hasil analisis WarpPLS Versi 5.0. menunjukan bahwa hipotesis pertama ditolak karena Arti pekerjaan berpengaruh negatif dan tidak signifikan terhadap kepuasan kerja. Hipotesis kedua diterima karena Kompetensi berpengaruh positif dan signifikan terhadap kepuasan kerja. Hipotesis Ketiga ditolak karena Kebebasan diri memiliki pengaruh negatif dan signifikan terhadap Kepuasan Kerja. Hipotesis Keempat ditolak karena Dampak memiliki pengaruh positif dan tidak signifikan terhadap Kepuasan Kerja

Kata kunci : Arti Pekerjaan, Kompetensi, Kebebasan Diri, Dampak, Kepuasan Kerja
\end{abstract}

\begin{abstract}
The objective of this study to explorating employee work work meaning, competence, Self actualization effect on employee satisfaction at PT Bank BRI (Persero) Tbk. Branch Ahmad Yani Makassar. Data collection used primary data obtained from questionnaires using saturated samples. The sample amounted to 70 respondents. The results of WarpPLS Version 5.0. showed that the first hypothesis was rejected because the meaning of work had a negative and insignificant effect on job satisfaction. The second hypothesis is accepted because Competence has a positive and significant effect on job satisfaction. The Third Hypothesis is rejected because Self-Freedom has a negative and significant influence on Job Satisfaction. The Fourth Hypothesis is rejected because the Impact has a positive and insignificant effect on Job Satisfaction
\end{abstract}

Keywords: $\quad$ work meaning, competence, selfactualization, job satisfaction

\section{Latar Belakang}

PT Bank BRI (Persero) Tbk Cabang Ahmad Yani Makassar sebagai salah satu bank milik pemerintah yang melayani nasabah dari semua golongan.Bank BRI adalah salah satu bank yang sangat gampang dijumpai disetiap plosok negeri ini. 


\section{JURNAL ORGANISASI DAN MANAJEMEN}

Issue 2 (Oktober, 2017)

Oleh sebab itu Bank BRI dikenal sebagai salah satu bank komersil dengan nasabah terbanyak di Indonesia. Bank ini juga melayani pemberian kredit usaha kepada masyarakat dengan bunga yang rendah.Dalam praktek sehari-hari pinjaman kredit dinyatakan dalam bentuk perjanjian tertulis baik dibawah tangan maupun secara materiil. Dan sebagai jaminan pengaman, pihak peminjam akan memenuhi kewajiban dan menyerahkan jaminan baik bersifat kebendaan maupun bukan kebendaan.

Teori Pengharapan (Expectancy Theory) Teori pengharapan dikembangkan oleh Victor H. Vroom yang menjelaskan bahwa "Motivasi merupakan suatu produk dari bagaimana seseorang menginginkan sesuatu, dan penaksiran seseorang memungkinkan aksi tertentu yang akan menuntunnya. Pengharapan merupakan kekuatan keyakinan pada suatu perlakuan yang diikuti dengan hasil khusus atau aksi yang berhubungan dengan hasil (Mangkunegara, 2000:122, dalam Sinollah, 2011). Teori tersebut menjelaskan bahwa tinggi ataupun rendahnya kepuasan kerja yang dirasakan oleh karyawan sangat ditentukan melalui pemberdayaan seseorang dalam pekerjaan, setiap individu dalam bekerja akan merasakan kepuasan apabila mereka diberdayakan oleh organisasi. Karyawan akan merasakan puas jika mereka memiliki pemahaman terhadap pekerjaannya, karyawan akan merasakan puas jika mereka memiliki kompentensi yang sesuai dengan pekerjaannya. Selanjutnya karyawan akan merasakan puas jika memiliki kebebasan diri dalam bekerja. dan yang terakhir karyawan akan merasakan puas jika memiliki kontribusi dalam pencapaian tujuan organisasi.

Kepuasan kerja merupakan keadaan emosional yang menyenangkan atau tidak menyenangkan oleh para karyawan mengenai pekerjaannya (Mangkunegara, 2000:122, dalam Sinollah, 2011). Kepuasan kerja adalah sikap yang seorang karyawan tentang pekerjaan dan organisasi di mana mereka melaksanakan pekerjaan tersebut, secara metodologis kepuasan kerja didefinisikan sebagai reaksi afektif karyawan untuk pekerjaan yang didasarkan pada perbandingan antara hasil aktual dan hasil yang diinginkan (Al-Zu'bi, 2010; dalam Srinadi, dkk., 2014). Tinggi rendahnya kepuasan kerja ditentukan oleh pengawasan, rekan kerja, gaji, promosi, dan pekerjaan itu sendiri (Tsai dan Huang, 2008; dalam Widayanti, dkk., 2016).

Salah satu faktor yang mempengaruhi kepuasan kerja yaitu pemberdayaan. Pemberdayaan merupakan pendekatan yang demokratis dimana pimpinan mendorong karyawan untuk ikut terlibat dalam pengambilan keputusan yang bersangkutan dengan pekerjaan (Ismail et al, 2011; dalam Widayanti, dkk., 2016). Penelitian mengenai hubungan pemberdayaan terhadap kepuasan kerjakaryawan mengacu pada peneliti (Styawahyuni, dkk., 2014 dan Srinadi, dkk., 2014) bahwa pemberdayaan berpengaruh positif dan signifikan terhadap kepuasan kerja. Hasil penelitian ini berbeda dengan peneliti (Lodjo, dkk., 2013) bahwa pemberdayaan tidak signifikan terhadap kepuasan kerja.

Fakta lapang diperoleh berdasarkan pra penelitian, bahwa kuliatas pelayanan yang diberikan oleh pihak PT Bank BRI kepada nasabah belum dilakukan dengan baik, hal ini disebabkan karena dana yang diberikan oleh pihak manajemen tidak memenuhi anggaran dalam melaksanakan pelatihan. Kondisi tersebut berdampak terhadap beberapa materi pelatihan yang tidak dapat diberikan kepada karyawan dengan baik, sehingga upaya penciptaan kualitas pelayanan yang prima tidak dapat dilakukan dengan optimal.

Pada sisi lainnya tingkat kepuasan kerja karyawan rendah, rendahnya kepuasan kerja karyawan disebabkan oleh banyak faktor, salah satu diantaranya

Halaman 48

Author : Bariya Samiun dkk. (Oktober, 2017). 47 - 61 


\section{JURNAL ORGANISASI DAN MANAJEMEN}

Issue 2 (Oktober, 2017)

pemberdayaan karyawan. Pemberdayaan karyawan yang dilakukan pada PT Bank BRI sifatnya masih kekeluargaan, karyawan yang diberdayakan adalah karyawan yang memiliki hubungan emosional dengan pimpinan, sehingga bagi karyawan yang tidak memiliki hubungan emosional tersebut merasa tidak puas.Ketidakpuasan tersebut mengakibatkan beberapa karyawan memilih untuk mengundurkan diri (resign).

Kepuasan kerja bisa dilihat atau dikatakan puas dalam bekerja jika pendapatan yang diperoleh telah dapat mencukupi kebutuhan pekerja tersebut, dan dalam perusahaan tersebut karyawan merasakan nyaman dalam bekerja dan tidak mempunyai kekhawatiran lain seperti kurang cukup gaji yang diterima, tidak adanya jaminan kesehatan/keselamatan kerja dan jaminan masa tua atau pensiun. Pemberdayaan sumber daya manusia adalah suatu proses kegiatan usaha untuk lebih memberdayakan "daya manusia" melalui perubahan dan pengembangan manusia itu sendiri, berupa kemampuan, kepercayaan, wewenang, dan tanggung jawab dan rangka pelaksanaan kegiatan-kegiatan organisasi untuk meningkatkan kinerja sebagaimana diharapkan (Sedarmayanti, 2007 dalam Suryadewi.,dkk, 2014).

\section{Tinjauan Pustaka}

\section{Pemberdayaan}

Pemberdayaan (empowerment) secara etimologis berasal dari kata daya yang berarti kemampuan untuk melakukan sesuatu atau kemampuan bertindak. Mendapat awalan ber- menjadi 'berdaya' artinya berkekuatan, berkemampuan, bertenaga, mempunyai akal (cara dan sebagainya) untuk mengatasi sesuatu (Suwatno dan Priansa, 2011:182). Khan (2007, dalam Suwatno dan Priansa, 2011) menjelaskan pemberdayaan merupakan hubungan antar personal yang berkelanjutan untuk membangun kepercayaan antar karyawan dan manajemen. Pemberdayaan karyawan (employee empowerment) menurut Mulyadi (2007:135) merupakan tren pengelolaan modal manusia di dalam organisasi masa depan.Ismail et al. (2011) menyatakan bahwa pemberdayaan karyawan merupakan pendekatan yang demokratis dimana pimpinan mendorong karyawan untuk ikut terlibat dalam pengambilan keputusan yang bersangkutan dengan pekerjaan.

\section{Kepuasan Kerja}

Mangkunegara (2007) mengemukakan bahwa "job satiffaction is the favor ableness or unfavorableness with employee view their work" (kepuasan kerja adalah perasaan menyokong atau tidak menyokong yang dialami karyawan dalam bekerja). Sutrisno (2010), mengemukakan kepuasan kerja adalah keadaan emosional yang menyenangkan atau tidak menyenangkan bagi para karyawan memandang pekerjaan.Kepuasan kerja mencerminkan perasaan seseorang terhadap pekerjaan.Hal ini tampak dalam sikap positif karyawan terhadap pekerjaan dan segala sesuatu yang dihadapi di lingkungan kerja.Husain Umar (2008), menyatakan bahwa :Kepuasan kerja adalah perasaan dan penilaian seorang atas pekerjaannya, khususnya menegenai kondisi kerjanya, dalam hubungannya dengan apakah pekerjaannya mampu memenuhi harapan, kebutuhan, dan keinginannya.

Dari definisi-definisi para ahli di atas, dapat disimpulkan bahwa kepuasan kerja (job satisfaction) adalah keadaan emosional atau respon afektif seseorang terhadap berbagai situasi dan kondisi kerja yang dapat harapan yang dihadapi bagi 
Issue 2 (Oktober, 2017)

para karyawan dalam memandang pekerjaan memenuhi segala yang berkaitan dengan kebutuhan, keinginan dan tersebut.

\section{Metode Penelitian}

Penelitian ini termasuk penelitian metode deskriptif kuantitatif yang bertujuan untuk menjelaskan suatu fenomena empiris yang disertai data statistic dan pola hubungan antara variabel. Penelitian ini menggunakan analisis SEM (Structural equation modeling) dibantu dengan WaphPLS Ver. 5.0 sebagai peralatan penelitian.

\section{Hasil Penelitian}

\section{Evaluasi Model Pengukuran (Outer Model) Model 1}

Evaluasi outer model dilakukan melalui 3 kriteria yaitu convergent validity, discriminant validity dan composite reliability. Convergent validity dari model pengukuran dapat dilihat dari korelasi antara skor indikator dengan skor konstruknya (loading factor) dengan kriteria nilai loadingfactor dari setiap indikator lebih besar dari 0,70 dapat dikatakan valid. Selanjutnyauntuk nilai p-value apabila < 0,05 dianggap signifikan. Loading factor antara 0,40-0,70 harus tetap dipertimbangkan untuk dipertahankan. Selanjutnya dijelaskan pula bahwa, indikator dengan loading $<0,40$ dihapus dari model. Penghapusan indikatordengan loading antara 0,40-0,70 dilakukan apabila indikator tersebut dapatmeningkatkan AVE dan composite reliability diatas nilai batasannya. Nilai batasan untuk AVE 0,50 dan composite reliability adalah 0,50 (Machfud dan Dwi, 2013: 66; dalam Ovi Arista, 2015). Hasil pengolahan Convergent Validity dapat dilihat pada tabel berikut ini:

Tabel 1. Hasil Output Combined Loading and Cross-Loading (model1)

\begin{tabular}{|c|c|c|c|c|c|c|c|}
\hline MODEL 1 & AR_X1 & KP_X2 & KD_X3 & DP_X4 & KK_Y & P value & Keterangan \\
\hline $\mathrm{X} 111$ & $(0.850)$ & -0.054 & -0.012 & 0.012 & -0.104 & $<0.001$ & Valid \\
\hline $\mathrm{X} 112$ & $(0.781)$ & 0.177 & -0.021 & -0.236 & 0.032 & $<0.001$ & Valid \\
\hline $\mathrm{X} 113$ & $(0.71)$ & -0.13 & 0.038 & 0.244 & 0.089 & $<0.001$ & Valid \\
\hline $\mathrm{X} 121$ & 0.066 & $(0.864)$ & 0.016 & -0.051 & 0.064 & $<0.001$ & Valid \\
\hline $\mathrm{X} 122$ & -0.143 & $(0.77)$ & -0.023 & -0.063 & 0.058 & $<0.001$ & Valid \\
\hline $\mathrm{X} 123$ & 0.071 & $(0.734)$ & 0.006 & 0.126 & -0.136 & $<0.001$ & Valid \\
\hline $\mathrm{X} 131$ & 0.072 & -0.132 & $(0.795)$ & 0.186 & -0.154 & $<0.001$ & Valid \\
\hline $\mathrm{X} 132$ & 0.01 & 0.007 & $(0.91)$ & 0.028 & 0.016 & $<0.001$ & Valid \\
\hline X133 & -0.087 & 0.131 & $(0.751)$ & -0.232 & 0.143 & $<0.001$ & Valid \\
\hline $\mathrm{X} 141$ & 0.071 & -0.275 & 0.187 & $(0.805)$ & 0.045 & $<0.001$ & Valid \\
\hline $\mathrm{X} 142$ & -0.033 & 0.09 & -0.087 & $(0.897)$ & -0.169 & $<0.001$ & Valid \\
\hline X143 & -0.042 & 0.213 & -0.11 & $(0.661)$ & 0.175 & $<0.001$ & Valid \\
\hline Y11 & 0.399 & 0.229 & -0.142 & 0.299 & $(0.297)$ & $<0.001$ & Tdk. Valid \\
\hline Y12 & -0.096 & -0.493 & 0.336 & 0.072 & $(0.654)$ & $<0.001$ & Valid \\
\hline Y13 & 0.283 & -0.083 & 0.02 & -0.225 & $(0.807)$ & $<0.001$ & Valid \\
\hline Y14 & -0.098 & 0.149 & -0.226 & 0.068 & $(0.835)$ & $<0.001$ & Valid \\
\hline Y15 & -0.24 & 0.234 & -0.005 & -0.013 & $(0.842)$ & $<0.001$ & Valid \\
\hline
\end{tabular}

Sumber : Data Primer (diolah WarpPLS 5.0, 2017)

Berdasarkan hasil pengolahan data pada tabel tersebut maka dapat di jelaskan nilai Convergent validity untuk konstruk arti pekerjaan $\left(\mathrm{X}_{1}\right)$. Pada pengujian convergent validity di model 1 , hasil pengolahan data tersebut menjelaskan bahwa 


\section{JURNAL ORGANISASI DAN MANAJEMEN}

Issue 2 (Oktober, 2017)

semua indikator pada dimensi arti pekerjaan telah memenuhi standar Convergent Validity dengan nilai $>0.60$, sehingga indikator tersebut tidak dikeluarkan dari model.

Convergent validity untuk konstruk kompetensi $\left(\mathrm{X}_{2}\right)$. Hasil pengolahan data pada model 1 diatas menjelaskan bahwa bahwa $\mathrm{X}_{121}, \mathrm{X}_{122}$, dan $\mathrm{X}_{123}$ telah memenuhi standar Convergent Validity dengan nilai $>0.70$, sehingga indikator tersebut tidak dikeluarkan dari model. Convergent validity untuk konstruk kebebasan diri $\left(\mathrm{X}_{3}\right)$. Hasil pengolahan data pada model 1 diatas menjelaskan bahwa bahwa $\mathrm{X}_{131}, \mathrm{X}_{132}$, dan $\mathrm{X}_{133}$ telah memenuhi standar Convergent Validity dengan nilai $>0.60$, sehingga indikator tersebut tidak dikeluarkan dari model.

Convergent validity untuk konstruk dampak $\left(\mathrm{X}_{4}\right)$. Pada Hasil pengolahan data pada model 1 diatas menjelaskan bahwa bahwa $\mathrm{X}_{141}$, dan $\mathrm{X}_{142}$, telah memenuhi standar Convergent Validity dengan nilai $>0.60$, sehingga indikator tersebut tidak dikeluarkan dari model, sedangkan untuk indikator $\mathrm{X}_{143}$ dengan Combined loadings and cross-loadings $<0.60$ tidak dikeluarkan dari model dengan alasan merujuk pada pendapat Chin (Sofyan dan Heri, 2011: 18) bahwa untuk indikator yang nilai loading factornya $>0,05$ dikatakan valid sebagai indikator yang mengukur konstruk. Sehingga tidak ada alasan yang kuat untuk mengeluarkan indikator tersebut dari model.

Convergent validity untuk konstruk kepuasan kerja karyawan (Y). Pada Hasil pengolahan data pada model 1 diatas menjelaskan bahwa bahwa $Y_{12}, Y_{13}$. $Y_{14}$ dan $Y_{15}$, telah memenuhi standar Convergent Validity dengan nilai $>0.70$, sehingga indikator tersebut tidak dikeluarkan dari model, sedangkan $\mathrm{Y}_{11}$ tidak memenuhi standar Convergent Validity dengan nilai $<0.70$, sehingga indikator tersebut dikeluarkan dari model. Berdasarkan penjelasan tersebut maka hasil pengujian Convergent validity pada model 1 masih terdapat indikator yang tidak memenuhi standar corvergent validity yaitu pada indikator variabel kepuasan kerja $\left(\mathrm{Y}_{11}\right)$ dengan nilai sebesar $\mathrm{Y}_{11}=$ $0,297<0,70$, sehingga dilakukan pengujian model 2 .

Pengukuran lainnya dari convergent validity adalah dengan melihat nilai AVE (Average Variance Extracted). Menurut pendapat (Mahfud Sholihin dan Dwi Ratmono (2013: 73), dalam Arista, 2015) menyatakan bahwa AVE (Average Variance Extracted) juga digunakan untuk evaluasi validitas konvergen, kriteria yang harus dipenuhi yaitu nilai AVE $>0,50$.

\section{Evaluasi Model Pengukuran (Outer Model) Model 2}

Pada model 2 yaitu evaluasi outer model dilakukan melalui 3 kriteria yaitu convergent validity, discriminant validity dan composite reliability. Berikut ini adalah hasil pengolahan data:

a. Convergent Validity (Validitas Konvergen)

Convergent validity dari model pengukuran dapat dilihat dari korelasi antaraskor indikator dengan skor konstruknya (loading factor) dengan kriteria nilailoading factor dari setiap indikator lebih besar dari 0,70 dapat dikatakan valid.Selanjutnya untuk nilai p-value apabila < 0,05 dianggap signifikan Hasil pengolahan Convergent Validity dapat dilihat pada tabel berikut ini: 
Issue 2 (Oktober, 2017)

Table 2 Hasil output combined loadings and cross-loading

\begin{tabular}{|c|c|r|r|r|r|c|c|}
\hline MODEL 2 & \multicolumn{1}{|c|}{ AR_X1 } & \multicolumn{1}{c|}{ KP_X2 } & \multicolumn{1}{|c|}{ KD_X3 } & \multicolumn{1}{|c|}{ DP_X4 } & \multicolumn{1}{c|}{ KK_Y } & P value & Keterangan \\
\hline X111 & $(0.85)$ & -0.059 & -0.007 & 0.001 & -0.116 & $<0.001$ & Valid \\
\hline X112 & $(0.781)$ & 0.178 & -0.023 & -0.233 & 0.033 & $<0.001$ & Valid \\
\hline X113 & $(0.71)$ & -0.126 & 0.034 & 0.255 & 0.103 & $<0.001$ & Valid \\
\hline X121 & 0.066 & $(0.864)$ & 0.016 & -0.051 & 0.063 & $<0.001$ & Valid \\
\hline X122 & -0.135 & $(0.77)$ & -0.026 & -0.058 & 0.06 & $<0.001$ & Valid \\
\hline X123 & 0.064 & $0.734)$ & 0.008 & 0.121 & -0.137 & $<0.001$ & Valid \\
\hline X131 & 0.093 & -0.135 & $(0.795)$ & 0.194 & -0.131 & $<0.001$ & Valid \\
\hline X132 & 0.003 & 0.007 & $(0.91)$ & 0.025 & 0.011 & $<0.001$ & Valid \\
\hline X133 & -0.102 & 0.135 & $(0.751)$ & -0.236 & 0.125 & $<0.001$ & Valid \\
\hline X141 & 0.091 & -0.273 & 0.186 & $(0.805)$ & 0.062 & $<0.001$ & Valid \\
\hline X142 & -0.031 & 0.085 & -0.084 & $(0.897)$ & -0.162 & $<0.001$ & Valid \\
\hline X143 & -0.068 & 0.217 & -0.113 & $(0.661)$ & 0.144 & $<0.001$ & Valid \\
\hline Y12 & -0.049 & -0.467 & 0.321 & 0.103 & $(0.683)$ & $<0.001$ & Valid \\
\hline Y13 & 0.329 & -0.052 & 0 & -0.192 & $(0.809)$ & $<0.001$ & Valid \\
\hline Y14 & -0.052 & 0.175 & -0.243 & 0.098 & $(0.84)$ & $<0.001$ & Valid \\
\hline Y15 & -0.227 & 0.259 & -0.019 & 0.003 & $(0.831)$ & $<0.001$ & Valid \\
\hline
\end{tabular}

Sumber : Data Primer (diolah WarpPLS Ver 5.0, 2017)

Hasil pada tabel diatas, menunjukkan hasil pengujian Convergent validity untuk model 2, dimana pada model 1 sebelumnya terdapat beberapa indikator pada variabel karakteristik individu, pemanfaatan teknologi informasi dan kinerja karyawan yang tidak memenuhi standar Convergent validity sehingga dilakukan pengujian model 2. Pada pengujian model 2 diatas, semua indikator yang tidak memenuhi standar Convergent validity telah dikeluarkan dari model, sehingga pengujian Convergent validity pada model 2 telah memenuhi standar Convergent Validity dengan nilai $>0.60$ dan P-value juga telah memenuhi syarat yaitu memiliki nilai sebesar $<0,001(<0,05)$ untuk seluruh indikator dari variabel Pemberdayaan, dan Kepuasan Kerja.

b. Uji Composite Reliability

Suatu variabel yang dipandang mampu (handal) dalam menjelaskan data dari variabel tersebut, pengujiannya dapat dilihat pada nilai composite reliability dan Cronbach's Alpha $<0,60$, untuk itu dapat diperlihatkan pada tabel berikut:

Table 3 Latent variable coefficients (composite reliability) (model 1)

\begin{tabular}{|l|r|r|r|r|r|}
\hline \multicolumn{1}{|c|}{ MODEL 2 } & \multicolumn{1}{c|}{ AR_X1 } & \multicolumn{1}{c|}{ KP_X2 } & \multicolumn{1}{c|}{ KD_X3 } & \multicolumn{1}{c|}{ DP_X4 } & \multicolumn{1}{c|}{ KK_Y } \\
\hline R-squared & & & & & 0.258 \\
\hline Adj. R-Squared & & & & & 0.212 \\
\hline Composite reliab & 0.825 & 0.833 & 0.861 & 0.834 & 0.871 \\
\hline Cronbach's alpha & 0.68 & 0.698 & 0.755 & 0.698 & 0.801 \\
\hline Avg. Var Extrac & 0.612 & 0.626 & 0.675 & 0.630 & 0.63 \\
\hline Full collin. VIF & 1.223 & 1.115 & 1.264 & 1.032 & 1.211 \\
\hline Q-squared & & & & & 0.268 \\
\hline
\end{tabular}

Sumber : Data Primer (diolah WarpPLS Ver 5.0, 2017)

Nilai composite reliability untuk dimensi arti pekerjaan sebesar 0,825 > 0,60 untuk dimensi kompetensi sebesar 0,833 >0,60, untuk dimensi kebebasan diri sebesar 0,861 >0,60, dan yang terakhir pada dimensi dampak sebesar 0,834>0,60. Selanjutnya untuk Cronbach's Alpha pada dimensi arti pekerjaan sebesar 0,68 > 0,60 , untuk dimensi kompetensi sebesar 0,698 $>0,60$, untuk dimensi kebebasan diri 
Issue 2 (Oktober, 2017)

sebesar 0,755 >0,60, dan yang terakhir pada dimensi dampak sebesar 0,698 >0,60. Untuk nilai Average Variances Extracted (AVE)/ nilai variasi rata-rata pada dimensi arti pekerjaan sebesar 0,612 $>0,50$, untuk dimensi kompetensi sebesar 0,626 $<0,50$, untuk dimensi kebebasan diri 0,675 >0,50, dan yang terakhir pada dimensi dampak sebesar 0,630>0,50. Berdasarkan hasil tersebut maka keseluruhan nilai memenuhi kriteria pengujian, sehingga terdapat cukup alasan yang kuat untuk mengujinya kembali pada model 2. memiliki alasan yang kuat untuk dianalisis lebih lanjut dimodel 2.

Tabel 4 Nilai AVE (Average Variance Extracted)

\begin{tabular}{|c|c|c|c|}
\hline Dimensi Laten & Nilai AVE & Kriteria & Keterangan \\
\hline AR_X1 & 0.612 & $>0,50$ & Memenuhi convergent validity \\
\hline KP_X2 & 0.626 & $>0,50$ & Memenuhi convergent validity \\
\hline KD_X3 & 0.675 & $>0,50$ & Memenuhi convergent validity \\
\hline DP_X4 & 0.630 & $>0,50$ & Memenuhi convergent validity \\
\hline KK_Y & 0.630 & $>0,50$ & Memenuhi convergent validity \\
\hline
\end{tabular}

Sumber : Data Primer (diolah WarpPLS Ver 5.0, 2017)

Berdasarkan hasil tersebut kelima konstruk telah memenuhi convergent validity. Arti pekerjaan dengan nilai 0,612 >0,50, kompetensi dengan nilai 0,626> 0,50 , kebebasan diri memiliki nilai 0,675 >0,50, dampak dengan nilai 0,630 >0,50, dan kepuasan kerja memiliki nilai 0,630 telah memenuhi nilai $>0,50$. Kesimpulannya keseluruhan variabel telah memenuhi kriteria convergent validity.

\section{c. Dicriminant Validity}

Discriminant validity dinilai dari cross loading pengukuran dengan konstruk. Dapat dilihat dengan melihat loading konstruk laten, yang akan memprediksi indikatornya lebih baik daripada konstruk lainnya. Jika korelasi konstruk dengan pokok pengukuran (setiap indikator) lebih besar daripada ukuran konstruk lainnya maka validitas diskriminan terpenuhi.

Tabel 5 Nilai loading konstruk laten indikator ke konstruk lainnya

\begin{tabular}{|c|c|c|c|c|c|c|}
\hline \multirow{2}{*}{ Indikator } & \multicolumn{7}{|c|}{ Nilai Loading ke konstruk lainnya } & \multirow{2}{*}{ Keterangan } \\
\cline { 2 - 6 } & AR_X1 & KP_X2 & KD_X3 & DP_X4 & KK_Y & Terpenuhi \\
\hline $\mathrm{X}_{111}$ & $(0.85)$ & -0.059 & -0.007 & 0.001 & -0.116 & Terpenuhi \\
$\mathrm{X}_{112}$ & $(0.781)$ & 0.178 & -0.023 & -0.233 & 0.033 & Terpenuhi \\
$\mathrm{X}_{113}$ & $(0.71)$ & -0.126 & 0.034 & 0.255 & 0.103 & Terpenuhi \\
\hline $\mathrm{X}_{121}$ & 0.066 & $0.864)$ & 0.016 & -0.051 & 0.063 & Terpenuhi \\
$\mathrm{X}_{122}$ & -0.135 & $(0.77)$ & -0.026 & -0.058 & 0.06 & Terpenuhi \\
$\mathrm{X}_{123}$ & 0.064 & $(0.734)$ & 0.008 & 0.121 & -0.137 & Terpenuhi \\
\hline $\mathrm{X}_{131}$ & 0.093 & -0.135 & $0.795)$ & 0.194 & -0.131 & Terpenuhi \\
$\mathrm{X}_{132}$ & 0.003 & 0.007 & $(0.91)$ & 0.025 & 0.011 & Terpenuhi \\
$\mathrm{X}_{133}$ & -0.102 & 0.135 & $0.751)$ & -0.236 & 0.125 & Terpenuhi \\
\hline $\mathrm{X}_{141}$ & 0.091 & -0.273 & 0.186 & $0.805)$ & 0.062 & Terpenuhi \\
$\mathrm{X}_{142}$ & -0.031 & 0.085 & -0.084 & $0.897)$ & -0.162 & Terpenuhi \\
$\mathrm{X}_{143}$ & -0.068 & 0.217 & -0.113 & $0.661)$ & 0.144 & Terpenuhi \\
\hline $\mathrm{Y}_{12}$ & -0.049 & -0.467 & 0.321 & 0.103 & $(0.683)$ & Terpenuhi \\
$\mathrm{Y}_{13}$ & 0.329 & -0.052 & 0.321 & -0.192 & $(0.809)$ & Terpenuhi \\
$\mathrm{Y}_{14}$ & -0.052 & 0.175 & -0.243 & 0.098 & $(0.84)$ & Terpenuhi \\
$\mathrm{Y}_{15}$ & -0.227 & 0.259 & -0.019 & 0.003 & $(0.831)$ & \\
\hline
\end{tabular}

Sumber : Data Primer (diolah WarpPLS Ver 5.0, 2017) 


\section{JURNAL ORGANISASI DAN MANAJEMEN}

Issue 2 (Oktober, 2017)

Berdasarkan data di atas, keseluruhan variabel independen dan dependen telah memenuhi kriteria validitas diskriminan. Variabel pemberdayaan (arti pekerjaan) yang memiliki 3 pernyataan yang dilambangkan dengan $\mathrm{X}_{111}, \mathrm{X}_{112}$, dan $\mathrm{X}_{113}$. Untuk pernyataan $\mathrm{X}_{111}$ memiliki nilai loading 0.85 yang nilai loading-nya lebih besar dari loading ke konstruk lain yaitu $-0.059,-0.007,0.001$, dan -0.116 serta ke 2 pernyataan arti pekerjaan lainnya juga memiliki nilai loading yang lebih besar dari nilai loading ke konstruk lain. Variabel pemberdayaan (kompetensi) yang memiliki 3 pernyataan yang dilambangkan dengan $\mathrm{X}_{121}, \mathrm{X}_{122}$, dan $\mathrm{X}_{123}$. Untuk pernyataan $\mathrm{X}_{121}$ memiliki nilai loading 0.864 yang nilai loading-nya lebih besar dari loading ke konstruk lain yaitu $0.066,0.016,-0.051$, dan 0.063 serta ke 2 pernyataan kompetensi lainnya juga memiliki nilai loading yang lebih besar dari nilai loading ke konstruk lain.

Variabel pemberdayaan (kebebasan diri) yang memiliki 3 pernyataan yang dilambangkan dengan $\mathrm{X}_{131}, \mathrm{X}_{132}$, dan $\mathrm{X}_{133}$. Untuk pernyataan $\mathrm{X}_{131}$ memiliki nilai loading 0.795 yang nilai loading-nya lebih besar dari loading ke konstruk lain yaitu $0.093,-0.135,0.194,-0.131$ serta ke 2 pernyataan arti kebebasan diri lainnya juga memiliki nilai loading yang lebih besar dari nilai loading ke konstruk lain. Variabel pemberdayaan (dampak) yang memiliki 3 pernyataan yang dilambangkan dengan $\mathrm{X}_{141}, \mathrm{X}_{142}$, dan $\mathrm{X}_{143}$. Untuk pernyataan $\mathrm{X}_{141}$ memiliki nilai loading 0. 0.805 yang nilai loading-nya lebih besar dari loading ke konstruk lain yaitu 0.091, $-0.273,0.186$, 0.062 serta ke 2 pernyataan arti dampak lainnya juga memiliki nilai loading yang lebih besar dari nilai loading ke konstruk lain.

Variabel kepuasan kerja memiliki 4 indikator yang dilambangkan dengan $\mathrm{Y}_{12}, \mathrm{Y}_{13}, \mathrm{Y}_{14}$ dan $\mathrm{Y}_{15}$. Untuk dimensi $\mathrm{Y}_{1}$ memiliki nilai loading 0,683 yang nilai loadingnya lebih besar dari loading ke konstruk lain yaitu $-0.049,-0.467,0.321,0.103$ serta ke 3 dimensi kepuasan kerja lainnya juga memiliki nilai loading yang lebih besar dari nilai loading ke konstruk lain. Berdasarkan uraian tersebut, dapat disimpulkan bahwa keseluruhan indikator telah memenuhi kriteria validitas diskriminan.

\section{Evaluasi Model Struktural (Inner Model)}

Tahap selanjutnya adalah melakukan evaluasi struktural (inner model) yang meliputi uji kecocokan model (model fit), path coefficient, dan R2. Pada uji kecocokan model terdapat 3 indeks pengujian, yaitu average path coefficient (APC), average Rsquared (ARS) dan average varians factor (AVIF) dengan kriteria APC dan ARS diterima dengan syarat $p$ - value $<0,05$ dan AVIF $<5$ (Mahfud Sholihin dan Dwi Ratmono, 2013: 61). Berikut ini adalah hasil output model fit indices yang disajikan dalam bentuk tabel yaitu:

Table 6 Hasil output model fit indices

\begin{tabular}{|l|l|l|l|}
\hline & \multicolumn{1}{|c|}{ Indeks } & \multicolumn{1}{c|}{$\boldsymbol{P}$-Value } & \multicolumn{1}{c|}{ Kriteria } \\
\hline APC & 0,205 & $\mathrm{P}<0,018$ & $\mathrm{P}<0,05$ \\
\hline ARS & 0,253 & $\mathrm{P}<0,006$ & $\mathrm{P}<0,05$ \\
\hline AVIF & 1,066 Acceptable if $<5$ & & $\mathrm{AVIF}<5$ \\
\hline
\end{tabular}

Sumber : Data Primer (diolah WarpPLS Ver 5.0, 2017)

Hasil output di atas, menjelaskan bahwa APC memiliki indeks sebesar 0,205 dengan nilai $\mathrm{p}$ - value $<0,018$. Sedangkan ARS memiliki indeks sebesar 0,253 dengan $\mathrm{p}$ - value $<0,006$. Berdasarkan kriteria, APC sudah memenuhi kriteria karena memiliki nilai $\mathrm{p}<0,018$. Begitu pula dengan nilai $\mathrm{p}$ dari ARS yaitu $\mathrm{p}<0,006$. 
Issue 2 (Oktober, 2017)

Nilai AVIF yang harus $<5$ sudah terpenuhi karena berdasarkan data tersebut AVIF nilainya 1,066. Dengan demikian, maka inner model dapat diterima.

\section{a. Hasil Uji Hipotesis}

Hasil korelasi antar konstruk diukur dengan melihat path coefficients dan tingkat signifikansinya yang kemudian dibandingkan dengan hipotesis penelitian yang terdapat di bab dua. Tingkat signifikansi yang dipakai dalam penelitian ini adalah sebesar 5\%. Berikut ini hipotesis yang dimaksudkan untuk membuktikan kebenaran dugaan penelitian yang terdiri dari tiga hipotesis, yaitu:

$\mathrm{H}_{1}=$ Pemberdayaan pada dimensi arti kerja berpengaruh positif dan signifikan terhadap kepuasan kerja karyawan

$\mathrm{H}_{2}=$ Pemberdayaan pada dimensi kompetensi berpengaruh positif dan signifikan terhadap kepuasan kerja karyawan

$\mathrm{H}_{3}=$ Pemberdayaan pada dimensi kebebasan diri berpengaruh positif dan signifikan terhadap kepuasan kerja karyawan

$\mathrm{H}_{4}=$ Pemberdayaan pada dimensi dampak berpengaruh positif dan signifikan terhadap kepuasan kerja karyawan

Berikut ini tabel hasil penelitian dari effect size yang telah diperoleh berdasarkan pengolahan data:

Gambar 1 Full Model

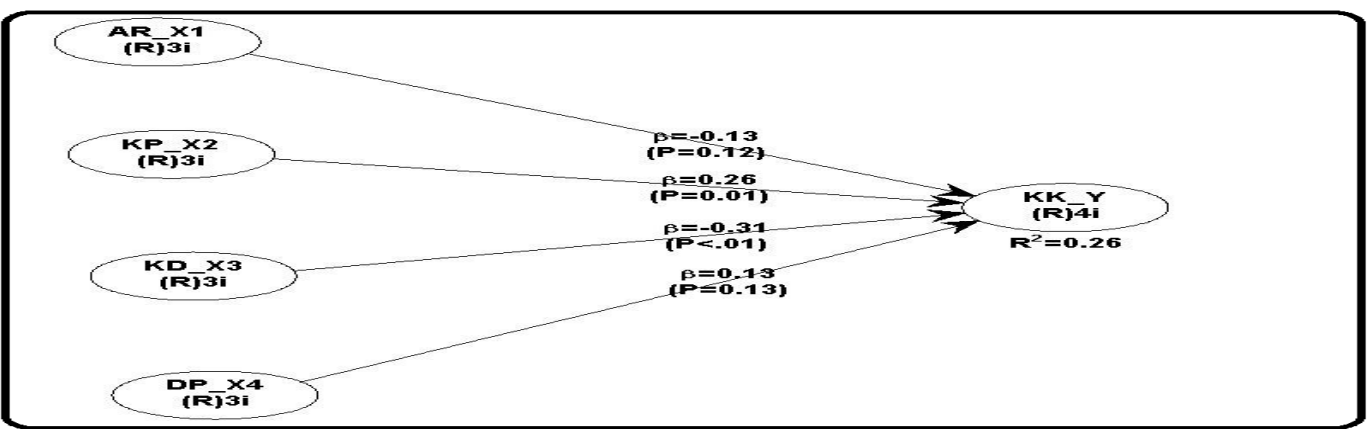

Sumber: Data primer (diolah WarphPLS Ver 5.0, 2017)

Berikut ini tabel hasil pengujian hipotesis yang telah diperoleh berdasarkan pengolahan data:

Table 7. Pengujian hipotesis

\begin{tabular}{|c|c|c|c|c|c|c|}
\hline Kriteria & Variabel & AR_X1 & KP_X2 & KD_X3 & DP_X4 & KK_Y \\
\hline \multirow[t]{5}{*}{ Path coefficients } & AR_X1 & - & - & - & - & - \\
\hline & KP_X2 & - & - & - & - & - \\
\hline & KD_X3 & - & - & - & - & - \\
\hline & DP_X4 & - & - & - & - & - \\
\hline & KK_Y & -0.133 & 0.259 & -0.313 & 0.13 & - \\
\hline \multirow[t]{5}{*}{ Pvalues } & AR_X1 & - & - & - & & - \\
\hline & KP_X2 & - & - & - & & - \\
\hline & KD_X3 & - & - & - & & - \\
\hline & DP_X4 & - & - & - & & - \\
\hline & KK_Y & 0.124 & 0.011 & 0.002 & 0.129 & - \\
\hline \multirow[t]{5}{*}{ Effect sizes for path } & AR_X1 & - & - & - & - & - \\
\hline & KP_X2 & - & - & - & - & - \\
\hline & KD_X3 & - & - & - & - & - \\
\hline & DP_X4 & - & - & - & - & - \\
\hline & KK_Y & 0.028 & 0.08 & 0.121 & 0.028 & - \\
\hline
\end{tabular}

Sumber: Data primer (diolah WarphPLS Ver 5.0, 2017)

Author : Bariya Samiun dkk. (Oktober, 2017). 47 - 61 


\section{JURNAL ORGANISASI DAN MANAJEMEN}

Issue 2 (Oktober, 2017)

Hasil tersebut di atas, menjelaskan bahwa path coefficients untuk dimensi arti pekerjaan terhadap kepuasan kerja memiliki indeks sebesar $-0,133$ dengan nilai $p$ - value 0,124 dan nilai effect size for path 0,028, untuk path coefficients dimensi kompetensi terhadap kepuasan kerja memiliki indeks sebesar 0,259 dengan $p-$ value 0,011 dan nilai effect size for path 0,08, untuk path coefficients dimensi kebebasan diri terhadap kepuasan kerja memiliki indeks sebesar -0,313 dengan $p-$ value 0,002 dan nilai effect size for path 0,121 , dan untuk untuk path coefficients dimensi dampak terhadap kepuasan kerja memiliki indeks sebesar -0,13 dengan $p-$ value 0,129 dan nilai effect size for path 0,028. Berikut ini merupakan gambar hasil penelitian dari effect size yang telah diperoleh berdasarkan pengolahan data.

Table 8 Hasil uji hipotesis

\begin{tabular}{|c|c|c|c|c|c|}
\hline Hipotesis & Independen & Dependen & p-values & $\begin{array}{c}\text { Koefisien } \\
\text { Jalur }\end{array}$ & Keputusan \\
\hline $\mathrm{H}_{1}$ & $\begin{array}{c}\text { Arti } \\
\text { perkerjaan }\end{array}$ & & 0,124 & $-0,133$ & Ditolak \\
\hline $\mathrm{H}_{2}$ & Kompetensi & \multirow{4}{*}{ Kepuasan Kerja } & 0,011 & 0,259 & Diterima \\
\cline { 1 - 2 } \cline { 5 - 6 } $\mathrm{H}_{3}$ & \begin{tabular}{c} 
Kebebasan \\
\cline { 5 - 6 }
\end{tabular} & Diri & 0,002 & $-0,313$ & Ditolak \\
\hline $\mathrm{H}_{4}$ & Dampak & & 0,129 & 0,130 & Ditolak \\
\hline
\end{tabular}

Sumber: Data primer (diolah WarphPLS Ver 5.0, 2017)

Berdasarkan tabel hasil uji hipotesis di atas, dapat diperoleh:

1) Hipotesis 1 ditolak, artinya dimensi arti pekerjaan dominan memiliki pengaruh negatif dan tidak signifikan terhadap kepuasan kerja karyawan pada PT Bank BRI (Persero) Tbk. Cabang Ahmad Yani Makassar. Hal ini ditunjukkan dengan nilai beta $(\beta)$ sebesar 0,133 dengan nilai $p$-value 0,124 .

2) Hipotesis 2 diterima, artinya dimensi kompetensi dominan memiliki pengaruh positif dan signifikan terhadap kepuasan kerja karyawan pada PT Bank BRI (Persero) Tbk. Cabang Ahmad Yani Makassar. Hal ini ditunjukkan dengan nilai beta $(\beta)$ sebesar 0,011 dengan nilai $p$ value 0,259 .

3) Hipotesis 3 sebagian diterima, artinya dimensi kebebasan diri dominan memiliki pengaruh negatif dan signifikan terhadap kepuasan kerja karyawan pada PT Bank BRI (Persero) Tbk. Cabang Ahmad Yani Makassar. Hal ini ditunjukkan dengan dimensi kebebasan diri memiliki nilai beta $(\beta)$ sebesar $-0,313$ dengan nilai $p$ value 0.002 .

4) Uji hipotesis 4 ditolak, artinya dimensi dampak dominan memiliki pengaruh positif dan tidak signifikan terhadap kepuasan kerja karyawan pada PT Bank BRI (Persero) Tbk. Cabang Ahmad Yani Makassar. Hal ini ditunjukkan dengan dimensi dampak memiliki nilai beta $(\beta)$ sebesar 0,130 dengan nilai $p$-value 0.129 . 


\section{JURNAL ORGANISASI DAN MANAJEMEN}

Issue 2 (Oktober, 2017)

Tabel 9 Ringkasan model (model summary)

\begin{tabular}{|l|c|c|c|c|c|}
\hline \multicolumn{1}{|c|}{ Pengukuran } & AR_X1 & KP_X2 & KD_X3 & DP_X4 & KK_Y \\
\hline R-squared & & & & & 0.253 \\
\hline Adj. R-Squared & & & & & 0.207 \\
\hline Composite reliab & 0.825 & 0.833 & 0.861 & 0.834 & 0.829 \\
\hline Cronbach's alpha & 0.68 & 0.698 & 0.755 & 0.698 & 0.735 \\
\hline Avg. Var Extrac & 0.612 & 0.626 & 0.675 & 0.63 & 0.515 \\
\hline
\end{tabular}

Sumber: Data primer (diolah WarphPLS Ver 5.0, 2017)

Berdasarkan tabel diatas besaran pengaruh nilai $R$-squared pada dimensi arti pekerjaan, dimensi kompetensi, dimensi kebebasan diri, dam dimensi dampak terhadap kepuasan kerja karyawan adalah 0,253 (25,30\%) dan sisanya 74,70\% dipengaruhi oleh variabel lain yang tidak dianalisis dalam penelitian ini seperti motivasi kerja, kepemimpinan, komitmen organisasional dan variabel lainnya.

a. Pemberdayaan pada dimensi Arti Pekerjaan berpengaruh negatif dan tidak signifikan terhadap kepuasan kerja karyawan

Berdasarkan hasil penelitian, ditemukan bahwa Arti Pekerjaan memiliki pengaruh negatif dan tidak signifikan terhadap Kepuasan Kerja. Hasil ini tidak sejalan dengan teori atau temuan dalam penelitian sebelumnya oleh Styawahyuni, (2014) meberikan arti bahwa Pemberdayaan karyawan(arti pekerjaan) secara parsial berpengaruh positif dan signifikan terhadap kepuasan kerja karyawan. Dalam penelitian ini dapat dilihat dari nilai koefisien beta yang menunjukkan bahwa semakin menurun arti pekerjaan maka semakin menurun juga Kepuasan Kerja yaitu dengan nilai beta $(\beta)$ sebesar -0.133 .

Hal ini menunjukkan bahwa dimensi Arti pekerjaan tidak dapat memengaruhi peningkatan Kepuasan kerja kearah yang lebih tinggi. Penyebab Negatif dan tidak signifikannya pengaruh Arti Pekerjaan terhadap Kepuasan Kerja diakibatkan karena kuliatas pelayanan yang diberikan oleh pihak PT Bank BRI kepada nasabah belum dilakukan dengan baik, hal ini disebabkan karena dana yang diberikan oleh pihak manajemen tidak memenuhi anggaran dalam melaksanakan pelatihan. Kondisi tersebut didukung dengan pemahaman Karyawan yang rendah terhadap tugas yang diberikan dan kemampuan karyawan menyelesaikan pekerjaan secara tepat waktu sehingga berdampak nyata terhadap tuntutan pekerjaan untuk dapat diselesaikan dengan cepat dan sesuai dengan standar kerja yang ditetapkan pada PT Bank BRI.

b. Pemberdayaan pada dimensi Kompetensi berpengaruh positif dan signifikan terhadap kepuasan kerja karyawan

Berdasarkan hasil penelitian, ditemukan bahwa Kompentensi memiliki pengaruh posistif dan signifikan terhadap Kepuasan Kerja. Hasil ini sejalan dengan teori atau temuan dalam penelitian sebelumnya oleh Styawahyuni, (2014) meberikan arti bahwa Pemberdayaan karyawan(Kompetensi) secara parsial berpengaruh positif dan signifikan terhadap kepuasan kerja karyawan.

Dalam penelitian ini dapat dilihat dari nilai koefisien beta yang menunjukkan bahwa semakin meningkatnya Kompentensi maka semakin meningkatnya Kepuasan Kerja yaitu dengan nilai beta $(\beta)$ sebesar 0.259 . Hal ini menunjukkan bahwa Dimensi Kompetensi dapat mempengaruhi peningkatan

Author : Bariya Samiun dkk. (Oktober, 2017). 47 - 61 


\section{JURNAL ORGANISASI DAN MANAJEMEN}

Issue 2 (Oktober, 2017)

Kepuasan kerja kearah yang lebih tinggi. Penyebab Positif dan signifikannya pengaruh Kompetensi terhadap Kepuasan Kerja diakibatkan karena PT. Bank BRI dapat mencukupi kebutuhan pekerja tersebut, dan dalam perusahaan tersebut Karyawan merasakan nyaman dalam bekerja dan tidak mempunyai kekhawatiran lain seperti kurang cukup gaji yang diterima, tidak adanya jaminan kesehatan/keselamatan kerja dan jaminan masa tua atau pensiun. Kondisi tersebut didukung dengan kesiapan Karyawan terhadap tugas yang diberikan dan kesadaran Karyawan menyelesaikan pekerjaan secara tepat waktu sehingga berdampak nyata terhadap tuntutan pekerjaan untuk dapat diselesaikan dengan cepat dan sesuai dengan standar kerja yang ditetapkan pada PT Bank BRI.

\section{c. Pemberdayaan pada dimensi Kebebasan Diri berpengaruh negatif dan Signifikan terhadap kepuasan kerja karyawan}

Berdasarkan hasil penelitian, ditemukan bahwa Kebebasan diri memiliki pengaruh negatif dan signifikan terhadap Kepuasan Kerja. Hasil ini tidak sejalan dengan teori atau temuan dalam penelitian sebelumnya oleh Styawahyuni, (2014) memberikan arti bahwa Pemberdayaan karyawan (Kebebasan Diri) secara parsial berpengaruh positif dan signifikan terhadap kepuasan kerja karyawan.

Dalam penelitian ini dapat dilihat dari nilai koefisien beta yang menunjukkan bahwa semakin menurun Kebebasan diri maka semakin menurun juga Kepuasan Kerja yaitu dengan nilai beta $(\beta)$ sebesar -0,313. Hal ini menunjukkan bahwa Dimensi Kebebasan diri dapat mempengaruhi peningkatan Kepuasan kerja kearah negatif. Penyebab Negatif dan signifikannya pengaruh Kebebasan Diri terhadap Kepuasan Kerja diakibatkan karena Karyawan dalam menyelesaikan pekerjaan dilakukan dengan kurang baik diakibatkan karena tidak adanya inovasi yang berdampak pada solidaritas Karyawan yang senantiasa menjalin kerjasama yang baik dengan para atasan. Kondisi tersebut didukung dengan ketidaksediaan Karyawan yang profesional dalam perusahaan dan dalam mengidentifikasi permasalahan yang terjadi, Karyawan perlu dibantu oleh tenaga ahli pada bidangnya sehingga berdampak nyata terhadap adanya inovasi dalam membantu menyelesaikan pekerjaan dan membantu sesama rekan kerja dengan mengeluarkan ide dan gagasan yang cukup menarik dalam menunjang peningkatan kepuasan kerja PT. Bank BRI.

\section{d. Pemberdayaan pada dimensi Dampak berpengaruh Positif dan tidak signifikan terhadap kepuasan kerja karyawan}

Berdasarkan hasil penelitian, ditemukan bahwa Dampak memiliki pengaruh positif dan tidak signifikan terhadap Kepuasan Kerja. Hasil ini tidak sejalan dengan teori atau temuan dalam penelitian sebelumnya oleh Styawahyuni, (2014) memberikan arti bahwa Pemberdayaan karyawan (Kebebasan Diri) secara parsial berpengaruh positif dan signifikan terhadap kepuasan kerja karyawan. Dalam penelitian ini dapat dilihat dari nilai koefisien beta yang menunjukkan bahwa semakin meningkatnya Dampak maka semakin meningkatnya Kepuasan Kerja yaitu dengan nilai beta $(\beta)$ sebesar 0,130 .

Hal ini menunjukkan bahwa Dimensi Dampak dapat mempengaruhi peningkatan Kepuasan kerja kearah Positif. Penyebab positif dan tidak signifikannya pengaruh Dampak terhadap Kepuasan Kerja diakibatkan karena perusahaan yang menerapkan pendidikan dan pelatihan mampu membentuk kemampuan karyawan dengan baik, sehingga dapat mempengaruhi kepuasan kerja karyawan. Kepuasan 


\section{JURNAL ORGANISASI DAN MANAJEMEN}

Issue 2 (Oktober, 2017)

kerja berdampak baik pada tujuan yang ingin dicapai perusahaan sehingga dapat mensejahterakan perusahaan dan pihak berkepentingan lainnya sehingga perlunya peningkatan pemberdayaan dalam dimensi dampak kerja pada karyawan yang tinggi.

\section{Kesimpulan}

Arti pekerjaan berpengaruh negatif dan tidak signifikan terhadap kepuasan kerja. Kondisi tersebut disebabkan karena Arti pekerjaan tidak dapat memengaruhi Kepuasan kerja kearah yang lebih tinggi. Penyebab Negatif dan tidak signifikannya pengaruh Arti Pekerjaan terhadap Kepuasan Kerja diakibatkan karena kuliatas pelayanan yang diberikan oleh pihak PT Bank BRI kepada nasabah belum dilakukan dengan baik, hal ini disebabkan karena dana yang diberikan oleh pihak manajemen tidak memenuhi anggaran dalam melaksanakan pelatihan. Kompetensi berpengaruh positif dan signifikan terhadap kepuasan kerja. Kondisi tersebut disebabkan karena Dimensi Kompetensi dapat mempengaruhi peningkatan Kepuasan kerja kearah yang lebih tinggi. Penyebab Positif dan signifikannya pengaruh Kompetensi terhadap Kepuasan Kerja diakibatkan karena PT. Bank BRI dapat mencukupi kebutuhan pekerja tersebut, dan dalam perusahaan tersebut Karyawan merasakan nyaman dalam bekerja dan tidak mempunyai kekhawatiran lain seperti kurang cukup gaji yang diterima, tidak adanya jaminan kesehatan/keselamatan kerja dan jaminan masa tua atau pension. Kebebasan diri memiliki pengaruh negatif dan signifikan terhadap Kepuasan Kerja. Kondisi tersebut disebabkan karena Dimensi Kebebasan diri dapat mempengaruhi peningkatan Kepuasan kerja kearah negatif. Penyebab Negatif dan signifikannya pengaruh Kebebasan Diri terhadap Kepuasan Kerja diakibatkan karena Karyawan dalam menyelesaikan pekerjaan dilakukan dengan kurang baik diakibatkan karena tidak adanya inovasi yang berdampak pada solidaritas Karyawan yang senantiasa menjalin kerjasama yang baik dengan para atasan. Dampak memiliki pengaruh positif dan tidak signifikan terhadap Kepuasan Kerja. Kondisi tersebut disebabkan karena Dimensi Dampak dapat mempengaruhi peningkatan Kepuasan kerja kearah Positif. Penyebab positif dan tidak signifikannya pengaruh Dampak terhadap Kepuasan Kerja diakibatkan karena perusahaan yang menerapkan pendidikan dan pelatihan mampu membentuk kemampuan karyawan dengan baik, sehingga dapat mempengaruhi kepuasan kerja karyawan.

Disarankan kepada peneliti lanjutan agar objek penelitian sebaiknya diperluas, sehingga hasil yang diperoleh lebih maksimal dan lebih dapat memberikan gambaran yang lebih jelas mengenai pengaruh Pemberdayaan terhadap Kepuasan kerja secara menyeluruh. Dalam hal waktu, hendaklah peneliti selanjutnya dapat memiliki waktu yang cukup untuk melakukan penelitian sehingga bisa mencapai hasil yang maksimal. Peneliti selanjutnya diharapkan dapat menambah beberapa variabel independen lainnya agar variabel tersebut mampu menjelaskan variabel dependen lebih besar dari penelitian sebelumnya sehingga mendapatkan hasil yang lebih akurat. Disarankan kepada PT. Bank BRI untuk lebih meningkatkan pengimplementasian Pemberdayaan dalam menunjang Kepuasan kerja yang lebih optimal.

\section{DAFTAR PUSTAKA}

Akra, M., Shahid, M., And Khan, A. (2007). Etiology And Antibiotic Resistance Patterns of Community-Acquired Urinary Tract Infections In J N M C Hospital Aligarh, India.

Halaman 59

Author : Bariya Samiun dkk. (Oktober, 2017). 47 - 61 
Issue 2 (Oktober, 2017)

Al-Zu'bi, H. A. (2010). A Study Of Relationship Between Organizational Justice And Job Satisfaction. International Journal of Business And Management, Vol 5, Pp. 102-109.

Arikunto, S (2002). Prosedur Penelitian, Suatu Pendekatan Praktek. Jakarta: PT. Rineka Cipta.

Augusty, Ferdinand. (2006). Metode Penelitian Manajemen: Pedoman Penelitian Untuk Skripsi, Tesis Dan Disertai Ilmu Manajemen. Semarang: Unirversitas Diponegoro.

Bambang Prasetyo Dan Lina Miftahul Jannah. (2005). Metode Penelitian. Kuantitatif:Teori Dan Aplikasi. Jakarta: Penerbit PT.Raja Grafindo.

Ghozali, Imam. 2011. "Aplikasi Analisis Multivariate Dengan Program SPSS". Semarang: Badan Penerbit Universitas Diponegoro.

Hartono, Jogiyanto. (2004).Metodologi Penelitian Bisnis, Edisi 2004-2005, BPFE,. Yogyakarta.

Ismail, A., Mohamed, H., Sulaiman, A.Z., Mohamad, M.H., And Yusuf, M.H. (2011).An Empirical Study of The Relationship Between Transformational Leadership, Empowerment And Organizational Commitment, Business And Economics Research Journal, Vol 2, No 1, Pp. 89-107.

Lodjo, Fernando Stefanus. (2013). "Pengaruh Pelatihan, Pemberdayaan Dan Efikasi Diri Terhadap Kepuasan Kerja". Skripsi.Universitas Sam Ratulangi.

Mangkunegara, A.A. Anwar Prabu.(2007), Manajemen Sumber Daya Manusia. Cetakan Ke Tujuh PT. Remaja Rosdakarya, Bandung. .(2000). Manajemen Sumber Daya Manusia. Perusahaan. Bandung : PT Remajarosdakarya.

Mulyadi. (2007). Sistem Perencanaan Dan Pengendalian Manajemen. Salemba. Empat. Jakarta.

Sadili, Samsudin, (2009). Manajemen Sumber Daya Manusia. Bandung : CV Pustaka Setia.

Safroni, Ladzi. (2012). Manajemen Dan Reformasi Pelayanan Publik Dalam Konteks Birokrasi Indonesia. Surabaya : Aditya Media Publishing

Sedarmayanti, (2007), Sumber Daya Manusia Dan Produktivitas Kerja, Bandung, Penerbit Mandar Maju

Sholihin, Mahfud Dan Ratmono, Dwi. (2013). Analisis SEM-PLS Dengan Wrap-PLS 3.0 Untuk Hubungan Nonlinear Dalam Penelitian Sosial Dan Bisnis. Yogyakarta: Penerbit ANDI.

Sinollah. (2011). Pengaruh Kompensasi Terhadap Kepuasan Kerja Karyawan (Studipada PT. PLN (Persero) Distribusi Jawa Timur Ap \& J Pasuruan). Jurnal Otonomi.

Soewedo (2009). Manajemen Perusahaan. Jakarta : PT. Rajagraf Indo Persada

Srinadi.(2014). Penerapan Metode Bermain Berbantuan Media Menara Angka Untuk Meningkatkan Perkembangan Kognitif. E- Journal PG-PAUD Universitas Pendidikan Ganesha.. Vol. 2 (1): Hal. 1-10.

Styawahyuni, Ari Danyuniari, Made. (2014). Pengaruh Pemberdayaan Karyawan Dan Streskerja Terhadap Kepuasan Kerja Karyawan. Jurnal Ekonomi Dan Bisnis

Sugiyono, (2007). Metodologi Penelitian Bisnis, PT. Gramedia, Jakarta. . (2010). Statistika Untuk Penelitian. Bandung: Alfabeta.

Suryadewi, Putuchori, I Ketut Dunia Dan Naswan Suharsono. (2014). Pengaruh Pemberdayaan Karyawan Terhadap Kinerja Karyawan Pada PT. Bali Segara Nusantara.Jurnal Ekonomi 
Issue 2 (Oktober, 2017)

Suwatno. \& Priansa, D. (2011). Manajemen SDM Dalam Organisasi Publik Dan Bisnis. Bandung: Alfabeta

Tsai, Tien Ming And Huang, Chen Chun.(2008).The Relationship Among Ethical Climate Types, Facets of Job Satisfaction, And The Three Components of Organizational Commitment: A Study Of Nurses In Taiwan. Journal Of Business Ethics, 80 Pp. 565-581.

Usman, Husaini. (2013). Manajemen :Teori, Praktik Dan Riset Pendidikan - Ed. 4, Cet.1-. Jakarta: Bumi Aksara.

Victor H. Vroom. (1964). Work And Motivation. New York : John Wiley \& Son, Inc.

Widayanti S N., Mappiratu, M. Danhardi, J., (2016), Optimalisasi Penerapan Bioetaknologi Dalam Produksi Bioetanol Dari Sagu (Metroxylon Sp.), Natural Sciences: Journal Of Science And Technology, 5(1): 41-48.

Yamin, Sofyan Dan Kurniawan, Heri. (2009). SPSS Complete, Jakarta: Salemba Empat .(2011).Generasi Baru Mengolah Data Penelitian Dengan Partial Least Square Path Modeling.Jakarta:Salembainfotek 